\title{
AVALIAÇÃO DO PESSOAL DE ENFERMAGEM NO HOSPITAL ANA NERY *
}

\author{
** Jandira Santos Orrico
}

RBEn/04

ORRICO, J.S. - Avaliação do pessoal de enfermagem no hospital Ana Nery. Rev. Bras. Enf.; DF, 31 : 304-311, 1978.

\section{INTRODUÇÃO}

A avaliação de desempenho dentro de uma organização é um instrumento valioso de desenvolvimento de seus recursos humanos. Com este objetivo em mente o Serviço de Enfermagem do Hospital Ana Nery, através da chefia, claborou um formulário de avaliação que denominou "Boletim de Avaliação".

A medida tornou-se imperiosa dado que se trata de um Hospital Geral, com 300 leitos, cujo Serviço de Enfermagem possui a lotação de 400 servidores.

Ao adotar este sistema o Serviço equipou-se com um elemento eficaz para o crescimento funcional de seus servidores e naturalmente espera que a resposta se traduza por participação e contribuição mais efetiva.

Esta ação está inteiramente de acordo com a política do governo de incentivo ao desempenho funcional através de promoções, bem como fornece elementos para que o Setor de Treinamento do Serviço de Enfermagem elabore seus programas dentro da real necessidade dos funcionários.

Entretanto, ao por em prática tal vrocedimento, não se desconhecia a complexidade que envolve um processo de avaliação pessoal. Sabia-se o quanto cie objetivação pode contribuir para fugir a uma realidade objetiva, dado que julgar envolve conhecimento do ser humano e o dimensionamento de seus valores.

\section{I - PASSOS PARA ELABORAÇAOO DO BOLETIM DE AVALIAÇAOO}

Para a elaboraçāo do "Boletim de Avaliação" tornou-se necessário determinar objetivos, treinar avaliadores e escolher o método de avaliação.

* Tema Livre apresentado no XXX CBEn - Belém - Pará - 1978.

** Chefe do Serviço de Enfermagem do Hospital Ana Nery - Salvador - BA. 
ORRICO, J.S. - Avaliação do pessoal de enfermagem no hospital Ana Nery. Rev. Bras. Enf.; DF, 31 : 304-311, 1978.

\section{1 - Objetivos}

Os objetivos estabelecidos visam, primordialmente, o desenvolvimento dos recursos humanos dentro do serviço:

a) definir o grau de contribuição do funcionário;

b) promover o auto desenvolvimento;

c) descobrir talentos e potencialidades, verificando os que têm condições de ocupar outras funçōes de maior conteúdo;

d) oferecer oportunidades para que 0 potencial se manifeste;

e) posicionar o funcionário em um trabalho onde possa render mais e estar mais satisfeito;

f) Identificar os que precisam de aperfeiçoamento em determinadas áreas de seu trabalho;

g) elaborar plano de ação para um desempenho satisfatório;

h) oferecer subsídios para promoção;

i) oferecer oportunidades para que o funcionário conheça seus pontos fracos e procure corrigir falhas.

\section{2 - Treinamento dos Avaliadores}

O julgamento do servidor é a fase mais difícil do processo de avaliação e esta depende sobremodo da competência das avaliadoras.

Por este motivo a Chefia de Enfermagem fez várias reuniōes com as chefias dos diversos setores do Serviço com a finalidade de orientá-las quanto aos objetivos, problemas e conceitos básicos que envolvem os critérios de avaliação.

Quanto a estes aspectos, vale destacar dois instrumentos que são essenciais:

\section{OBSERVAÇAO E COMUNICAÇAOO}

OBSERVAÇAO - Trata-se de uma tarefa difícil e que requer um conjunto de requisitos básicos entre os quais destacam-se: o respeito à pessoa humana, o preparo do observador e a utilização da técnica de observar.

A observação envolve dois aspectos principais: sensação e percepção, que se pode demonstrar diagramaticamente:
REGISTRO DE ONDAS RECEPÇAO DO ESTIMULO
- COMPREENSAO DA EXISTENCIA

- INTERPRETAÇAO DO REGISTRO SENSORIAL
SENSAÇÃO

Os pontos mais importantes deste processo são:

O que Observar - Como Observar

O QUE OBSERVAR - A enfermeira Chefe da Unidade tem melhor condições de avaliar, pois é a que maior contato mantém com o pessoal sob sua orientação. Ela observa o desempenho do servidor seguindo o roteiro lógico contido no "Boletim de Avaliação".
COMO OBSERVAR - necessário que a enfermeira desenvolva a capacidade de observar, considerando, naturalmente, o funcionário como ser humano.

t necesssário que a observação seja a mais objetiva possível para que fique mais próxima da realidade.

A observação deve ser periódica para permitir a obtenção de amostras mais significativas do desempenho do pes- 
ORRICO, J.S. - Avaliaçāo do pessoal de enfermagem no hospital Ana Nery. Rev. Bras. Enf.; DF, 31 : 304-311, 1978.

sn,al, favorecendo a correção de impressōes errôneas e a elaboração de conclusōes mais justas.

\section{DEFICIENCIAS DA AVALIAÇÃO}

Como se trata de "pessoas" a avaliar "pessoas", portadoras portanto de qualidades e defeitos é natural que ocorram inadequaçōes que podem ser minimizadas com treinamento e esforço por parte do avaliador.

As principais deficiências que podem ocorrer na avaliação são:

Efeito de Halo - Imperfeição que caracteriza-se pela tendência constante de se avaliar um funcionário porque "se pensa" que este indivíduo apresenta um desempenho desejável ou não no trabalho. Esta avaliação é baseada em suposiçōes.

Erro Constante - Ocorre quando determinados avaliadores registram sempre avaliaçōes muito altas ou baixas, 0 que resulta em mensuraçōes não criteriosas, refletindo personalidade condescendente ou não do avaliador.

Outra manifestação do erro constante é a adoção da posição central evitando deste modo os extremos superior ou inferior.

Efeito do Emocional - Não se pode desconhecer a influência que favoritismos, preferências, simpatias e antagonismos exercem na avaliação. Por esta razão há necessidade de neutralizar essas influências através de um julgamento objetivo e imparcial.

Comunicação - A comunicação é na enfermagem um dos mais importantes instrumentos de trabalho. "E uma forma canalizadora de energia para a interação grupal e um instrumento para propiciar as mudanças comportamentais". (1)
E imprescindível que o avaliador informe aos funcionários o resultado da avalição. Para que esta comunicação produza os efeitos desejados é necessário que seja feita de forma planejada, observando-se os princípios e procedimentos estabelecidos para a técnica de entrevista.

Durante este contato recomenda-se que $o$ avaliador:

- Apresente os aspectos positivos em primeiro lugar e os negativos posteriormente.

- Discuta os aspectos da avaliação, procurando estimular a aceitação de orientação ou ajuda.

- Elabore um plano com a participação do funcionário objetivando seu aperfeiçoamento profissional e pessoal.

\section{3 - Escolha do Método de Avaliação}

A escolha do método de avaliação recaiu no denominado "Escolha forçada" que minimiza o efeito de "Halo", subjetivismo, protecionismo, influências de personalidade e outras interferências.

Este método consiste em avaliar o desempenho por meio de frases descritivas de determinado tipo de desempenho do servidor em relação às tarefas que lhe foram atribuidas.

\section{ANALISE DO BOLETIM DE AVALIAÇÃO}

Foram feitos estudos e testes para a elaboração do Boletim de Avaliação ora em uso no Hospital Ana Nery, para o pessoal de Enfermagem.

Houve preocupação por parte dos elahoradores de torná-los o mais simples, claro e funcional possivel.

(1) RESENDE, Ana Lucia M. O Processo de Comunicaçāo como Instrumento de Enfermagem em Novas Dimensỏes, pg. 98. 
ORRICO, J.S. - Avaliação do pessoal de enfermagem no hospital Ana Nery. Rev. Bras. Enf.; DF, 31 : 304-311, 1978.

Ao lado do Boletim, tornou-se imperiosa a criação de "Fichas de Pessoal" onde são registradas, periodicamente, anotaçōes sobre a situação dos funcionários. Com isto evita-se que as avaliaçōes sejam feitas com base em julgamentos apressados ou de última hora.

Analisando o formulário apresentado, nota-se que os principais elementos a considerar são:

- ATITUDE PROFISSIONAL

- EFICIENCIA TÉCNICA

- CONHECIMENTO CIENTIFICO

aos quais são atribuídos conceitos:

- ÓTIMO

- BOM

- REGULAR ou

- DEFICIENTE

resultantes da média aritmética dos valores atribuídos aos itens que compōem cada elemento da avaliação.

Estes valores têm a seguinte correspondência:

- De 10 a 9 - Conceito ótimo

- De 8 a 7 - Bom

- De 5 a 6 - Regular

Abaixo de 5 - Deficiente.

\section{1 - Preenchimento do Boletim de Avaliação}

Para o preenchimento do Boletim de Avaliação cada elemento a ser estudado merece criterioso exame. Por esta razão, houve necessidade de desdobramento desses elementos de modo a tornar a avaliação a mais racional possivel:

\section{I - ATITUDE PROFISSIONAL}

No julgamento da atitude profissional do funcionário consideram-se vários pontos:

- Comportamento é a capacidade de relacionamento dentro do grupo a que pertence, destacando-se a sua atuação:
Diante da Chefia;

Diante dos demais membros da equipe;

Diante do paciente;

Diante da família do paciente;

Em outros setores do Hospital.

- Lealdade é a qualidade de assumir com fidelidade seus compromissos, ser franco e sincero, com a instituição e com os seus companheiros de trabalho.

- Responsabilidade é a capacidade de assumir as obrigaçōes que lhes são confiadas. Neste item leva-se em consideração:

Assiduidade

Pontualidade

Colaboração.

- Economia e zelo pelo material é a capacidade de executar as tarefas com mínimo de gasto e com menor desgaste possível.

- Dedicação é o zelo demonstrado por tudo que diz respeito à instituição.

- Interesse é a demonstração de conhecimento das principais atividades do serviço e a vontade de adquirir novos conhecimentos para 0 atendimento das necessidades futuras.

Este item está desdobrado em:

- Participação ativa na dinâmica do setor em cursos, palestras e discussōes.

- Reuniōes de serviço e Associação de classe.

- Consulta ao prontuário do paciente.

- Interroga sobre assunto de serviço.

- E criativo.

- Equilíbrio Emocional é a capacidade de manter o controle emocional o mais ajustado possivel às pessoas e circunstâncias.

- Disponibilidade é o estado de espírito caracterizado pela predisposição em aceitar as solicitaçōes do serviço.

- Discernimento é o ato de julgar as coisas com clareza e sensatez. 
ORRICO, J.S. - Avaliaçāo do pessoal de enfermagem no hospital Ans Nery. Rev. Brac.

Enf.; DF, 31 : 304-311, 1978.

- Iniciativa é a qualidade que revela a capacidade de conceber idéias, visualizar situaçōes novas no serviço, demonstração portanto, de Julgamento, planejamento, criação e execução.

- Receptividade é a capacidade de nianter bom ambiente de trabalho $e$ comportamento compreensivo e acolhedor.

- Ordem é o procedimento do servidor em relação a:

- Organização no Serviço leva-se em consideração a ordem e limpeza do material utilizado, conclusão das atividades com dedicação e presteza e utilização do tempo com racionalização.

- Aparência Pessoal considera-se a postura, uniforme e asseio corporal.

\section{II - EFICIENCIA TECNICA}

$\mathrm{Na}$ análise da Eficiência Técnica, observa-se:

- Habilidade é a capacidade que revela Inteligência, capacidade e aptidảo para determinado fim.

- Destreza é a agilidade de todos os movimentos.

\section{III - CONHECIMENTOS CIENTIFICOS}

Na avaliação do Conhecimento Clentífico, leva-se em consideraçāo:

Observação de Enfermagem.

Anotaçōes de Enfermagem - Documentos que servem de orlentaçäo para a equipe de saúde. Nota-se sobretudo neste item se são:

- Completas

- Concisas

- Dignas de nota

- Legíveis

- De linguagem correta

- Verdadeiras.

Aplicação dos princípios cientificos na Aplicação das Técnicas - é a capacicade de execução das técnicas do enfer- magem com segurança e levando-se em consideração os princípios científicos que as regem.

Orientação de Paciente - aptidão em assistir o paciente no atendimento de suas necessidades básicas (psicobiológicas, psicosociais e psicoespirituais). Isto requer do servidor de Enfermagem uma gama de conhecimentos cientificos $\mathrm{e}$ técnicos que o habilitam a desenvolver essa aptidão, dentro da sua capacidade intelectual e de escolaridade.

Educação em Saúde - leva-se em conta o interesse demonstrado pelo servidor em participar de reunióes, palestras ou cursos destinados a seu aproveitamento. Considera-se também o seu reconhecimento às necessidades de sucervisão e orientação.

\section{2 - Apuração dos Resultados}

Preenchidos todos os itens e atribuidos os valores e conceitos já estudados neste trabalho, a enfermelra, chefe responsável pela avaliação, discute com o servidor todos os itens do Boletim, destacando-se os pontos positivos. Fm seguida uma cópla é enviada à Chefla de Enfermagem que, em consonância com c Setor de Treinamento, promoverá as condiçōes necessárias para que o servidor tenha novas oportunidades de se capacitar para um melhor desempenho, estudará as potencialidades existentes ou determinará o tipo de apolo e assistência que se façam necessários.

\section{CONCLUSAOO}

A nossa tentativa neste trabalho fol divulgar a experiência adotada no Hospital Ana Nery e que até o momento, vem correspondendo às expectativas. Esperamos que ela sirva de subsidios para outras instituiçōes com as mesmas características da nossa e que porrentura, ainda não possuem um sistema de avaliação. 
ORRICO, J.S. - Avaliaçāo do pessoal de enfermagem no hospital Ana Nery. Rev. Bras. Enf.; DF, 31 : 304-311, 1978.

Vale ainda acrescentar que o método, sendo de natureza dinâmica, poderá sofrer alteraçōes sempre que se fizerem necessárias.

\section{RECOMENDAÇÓES}

As chefes de Serviço de Enpfermagem:

- que promovam meios para que os serviços disponham de um sistema de avaliação, imprescindível para a valorização do pessoal e atendimento à política do Governo de promoçōes funcionais.

As enfermeiras encarregadas da avaliação:

- que procurem desenvolver habilidades e atividades necessárias à avaliação de desempenho, através de cursos e treinamentos específicos.

\section{A NEXO}

I.N.P.S. - HOSPITAL ANA NERY

BOLETIM DE AVALIAÇÃO

Nome:

Mat.:

Sexo:

Data do nascimento:

Estado civil:

Instrução:

Endereço:

Cargo:

Data da admissão:

Unidade:

Outro emprego:

PONTOS A CONSIDERAR

CONCEITOS

OTIMO BOM REGULAR DEFICIENTE

ATITUDE PROFISSIONAL

EFICIENCIA TECNICA

CONHECIMENTO CIENTIFICO

IONCEITO GERAL:

Ass. da Chefe de Unidade ou Seção

Ass. do funcilonário 
ORRICO, J.S. - Avaliação do pessoal de enfermagem no hospital Ana Nery. Rev. Bras. Enf.; DF, 31 : 304-311, 1978.

\section{PONTOS A OBSERVAR}

I - Em ATITUDE PROFISSIONAL

1 - Etica

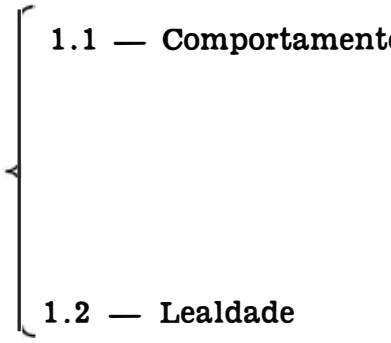
Diante da Chefia
Diante dos demais membros da equipe
Diante do Paciente
Diante dos familiares do Paciente
Em outros setores do Hospital

1.2 - Lealdade

2 - Responsabilidade:

Assiduidade

Pontualidade

Colaboração

Economia e zelo pelo material

Dedicação

3 - Interesse

Participa ativamente da dinâmica do setor Participa de cursos, palestras e discussōes quando surge oportunidade Consulta o prontuário do paciente Interroga sobre assuntos do Serviço f criativo

4 - Equilíbrio emocional

5 - Disponibilidade

6 - Discernimento

7 - Iniciativa

8 - Receptividade

9 - Ordem e Organização no Serviço Aparência pessoal

II - Em EFICIENCIA TECNICA

1 - Habilidade

2 - Destreza

III - Em CONHECIMENTO CIENTÍFICO

1 - Observaçōes de Enfermagem

2 - Anotaçōes de Enfermagem $\square$

3 - Aplicação dos princípios científicos na execução das técnicas

4 - Orientação de paciente

5 - Educação em Saúde 
ORRICO, J.S. - Avaliação đo pessoal de enfermagem no hospital Ana Nery. Rev. Bras. Enf.; DF, 31 : 304-311, 1978.

\section{BIBLIOGRAFIA}

1. ADAMI, N. P. Avaliaçāo de desempenho do pessoal de Enfermagem de Saúde Pública, Enfermagem, Novas Dimensōes, 3 (5) : 267-282, 1977.

2. FARIAS, Gonçalo P. Teoria Geral da Administraçāo, S. Paulo, Ed. Atlas, BNH 1977, $131 \mathrm{pg}$.

3. FERREIRA, Paulo, P. Administraçāo de Pessoal (Relaçōes Industriais), Sāo Paulo - Ed. Atlas S/A, 4.8 ed. 1977, 346 pgs.

4. LUCENA, Maria D. S."Avaliaçāo de De- sempenho, S. Paulo, Ed. Mac Graw Hill do Brasil Ltda., 1977, 177 pgs.

5. _ - - Treinamento de Supervisores em Avaliaçāo de Desempenho, Sāo Paulo - Ed. Atlas, 1971.

6. RESENDE, Ana Lúcia $M$. $O$ Processo de Comunicaçāo como Instrumental da Enfermagem, Novas Dimensōes, 2 (2) : 98:111, 1970.

7. RIBEIRO, Augusta B. C. Administraçāo de Pessoal nos Hospitais, Sāo Paulo, Ed. Mec., 2. ${ }^{\text {a }}$ ed., 1977, 700 pgs. 